\title{
Analise de trilha da massa da espiga de milho e seus atributos físicos
}

\author{
Analysis of the path of the corn cob mass and its physical attributes \\ Análisis del recorrido de la masa de mazorcas de maíz y sus atributos físicos
}

Recebido: 12/01/2021 | Revisado: 18/01/2021 | Aceito: 18/01/2021 | Publicado: 21/01/2021

Luana da Silva Pinheiro

ORCID: https://orcid.org/0000-0002-1192-989X

Universidade Federal Rural da Amazônia, Brasil

E-mail: luulupinheiro@hotmail.com

Regiane da Conceição Vieira

ORCID: https://orcid.org/0000-0001-9752-6196

Universidade Federal Rural da Amazônia, Brasil

E-mail: regiane.vieira.c11@gmail.com

Henrique da Silva Barata

ORCID: https://orcid.org/0000-0001-6356-4629

Universidade Federal Rural da Amazônia, Brasil

E-mail: henriquebarata2000@gmail.com

Rodrigo de Souza Mota

ORCID: https://orcid.org/0000-0003-2283-1019

Universidade Federal Rural da Amazônia, Brasil

E-mail: rodrigodmota@gmail.com

Raul Fortes Sousa

ORCID: https://orcid.org/0000-0003-1820-0572

Universidade Federal do Maranhão, Brasil

E-mail: raul_forttes@hotmail.com

Mateus Monteles Vieira

ORCID: https://orcid.org/0000-0003-3756-8946

Universidade Federal do Maranhão, Brasil

E-mail: mateusmv7@gmail.com

Maiane Rodrigues do Nascimento ORCID: https://orcid.org/0000-0002-4170-5694

Universidade Federal do Maranhão, Brasil

E-mail: maianerodrigues707@gmail.com

Vicente Filho Alves Silva

ORCID: https://orcid.org/0000-0003-2396-6986

Universidade Federal Rural daAmazônia, Brasil

E-mail: vicente.silva@ufra.edu.br

Job Teixeira de Oliveira

ORCID: https://orcid.org/0000-0001-9046-0382

Universidade Federal do Mato Grosso do Sul, Brasil

E-mail: job.oliveira@hotmail.com

Priscilla Andrade Silva

ORCID: https://orcid.org/0000-0002-2774-3192

Universidade Federal Rural da Amazônia, Brasil

E-mail: priscilla.andrade@ufra.edu.br

\begin{abstract}
Resumo
O milho faz parte da base alimentar do brasileiro. O objetivo deste estudo foi analisar os atributos que melhor representam a massa úmida da espiga do milho, através da análise de trilha, permitindo estabelecer correlações entre estas variáveis, que são indicativos de produtividade e qualidade do milho. O presente estudo foi realizado no município de Parauapebas-PA, nas dependências da área experimental do Centro Tecnológico da Agricultura Familiar (CETAF). Os atributos da espiga do milho foram: massa úmida da espiga (MAU), casca úmida da espiga (CAU), sabugo úmido (SAU), grão úmido da espiga (GRU), massa seca da espiga (MAS), massas do grão seco (GRS), sabugo seco (SAS) e casca seca da espiga (CAS). Resultados mostraram pela correlação de Pierson que casca úmida da espiga e massa úmida da espiga apresentaram uma alta correlação positiva. Como conclusões, a análise de trilha possibilitou verificar que, de forma direta, os atributos casca úmida e grãos úmidos da espiga são os atributos que melhor servem para avaliar a massa úmida da espiga do milho. Indiretamente, observamos via análise de trilha que a casca úmida tem correlação positiva com casca seca e massa seca da espiga e negativa com sabuco úmido e grãos secos da espiga.
\end{abstract}

Palavras-chave: Zea mayz L.; Multicolinearidade; Sistema de produção. 


\begin{abstract}
Corn is part of the Brazilian food base. The objective of this study was to analyze the attributes that best represent the wet mass of the corn cob, through the trail analysis, allowing to establish correlations between these variables, which are indicative of corn productivity and quality. This study was carried out in the municipality of Parauapebas-PA, on the premises of the experimental area of the Technological Center for Family Agriculture (CETAF). The attributes of the corn cob were: wet cob mass (MAU), wet cob husk (CAU), wet cob (SAU), wet cob grain (GRU), dry cob mass (MAS), dry grain masses (GRS), dry cob (SAS) and dry ear husk (CAS). Results showed by the Pierson correlation that that wet ear bark and wet ear mass showed a high positive correlation. As a conclusion, the trail analysis made it possible to verify that, directly, the attributes wet humid and wet grains of the ear are the attributes that best serve to evaluate the wet mass of the ear of corn. Indirectly, we observed via trail analysis that the wet peel has a positive correlation with dry peel and dry mass of the ear and negative with wet sabote and dry grains of the ear.
\end{abstract}

Keywords: Zea mayz L.; Multicollinearity; Production system.

\title{
Resumen
}

El maíz es parte de la base alimentaria brasileña. El objetivo de este estudio fue analizar los atributos que mejor representan la masa húmeda de la mazorca de maíz, a través del análisis de rastros, permitiendo establecer correlaciones entre estas variables, las cuales son indicativas de la productividad y calidad del maíz. Este estudio se realizó en el municipio de Parauapebas-PA, en las instalaciones del área experimental del Centro Tecnológico de Agricultura Familiar (CETAF). Los atributos de la mazorca de maíz fueron: masa de mazorca húmeda (MAU), cáscara de mazorca húmeda (CAU), mazorca húmeda (SAU), grano de mazorca húmeda (GRU), masa de mazorca seca (MAS), masas de grano seco (GRS), mazorca seca (SAS) y cascarilla seca (CAS). Los resultados mostraron por la correlación de Pierson que la corteza de la oreja húmeda y la masa de la oreja húmeda mostraron una alta correlación positiva. Como conclusión, el análisis de rastros permitió verificar que, directamente, los atributos mojado húmedo y granos mojados de la mazorca son los atributos que mejor sirven para evaluar la masa húmeda de la mazorca de maíz. Indirectamente, observamos a través del análisis de rastros que la piel húmeda tiene una correlación positiva con la piel seca y la masa seca de la mazorca y negativa con el sabote húmedo y los granos secos de la mazorca.

Palabras clave: Zea mayz L.; Multicolinealidad; Sistema de producción.

\section{Introduçãa}

O milho (Zea mays L.), originário da América Central e cultivado em todo o mundo. No Brasil, se destaca economicamente como importante cultura, utilizada como fonte de alimento, fibras, combustível e rações (Nardino, 2017). Segundo a companhia nacional de abastecimento (Conab, 2020) a produção dessas comodities vai alcançar a casa das 102,5 milhões de toneladas, e pressupõe-se 34,5 milhões de toneladas a serem exportadas, o que irá fortalecer mais ainda a economia do país, o consolidando como um dos maiores exportadores desse grão no mundo.

Números tão expressivos são alcançados graças a engenharia genética de sementes, ao manejo correto do solo, bem como a aquisição de novas máquina e tecnologias de produção. Fatores como, por exemplo, a modificação nas diferentes etapas produtivas, o manejo, por meio do preparo dos solos, adubação, sementes geneticamente modificadas (com alto potencial produtivo), época e métodos de semeadura, controle de plantas invasoras, pragas, doenças e tecnologias de colheita, possibilitam o incremento da produção (Artuzo et al., 2019).

Para Sukumar et al. (2019) o milho é um alimento que é encontrado em todo o mundo, sendo usado para consumo pelo homem, além de ser largamente empregado em diversas áreas, que vai desde a fabricação de etanol, produção de amido para culinária, produção de xarope, até nas fabricações de rações para bovinos e suínos, por apresentar grandes teores de nutrientes. Entre os principais atributos que conferem quantidades significativas de massa seca e suas variantes no estado úmido, seco ou verde destacam-se: os grãos, as espigas, o sabugo, a casca que envolve a espiga entre outros.

A análise de trilha permite que diferentes variáveis mantenham correlação entre si causando efeitos diretos e indiretos em função de uma variável principal, para efeito de produtividade e rendimento. A análise do coeficiente de correlação é uma técnica estatística que mede o grau e a associação entre duas ou mais variáveis. As estimativas do coeficiente de correlação são úteis na identificação das características dos componentes que podem ser usados para melhorar a produtividade do milho (Verma et al., 2020). 
Nesse sentido, o presente estudo tem como objetivo analisar os atributos que melhor representam a massa úmida da espiga do milho, através da análise de trilha, permitindo estabelecer correlações entre estas variáveis, que são indicativos de produtividade e qualidade do milho.

\section{Material e Métodos}

O presente estudo foi realizado no município de Parauapebas-PA, nas dependências da área experimental do Centro Tecnológico da Agricultura Familiar (CETAF), no período de 03 de março a 20 de junho de 2019, está situado na mesorregião Sudeste desse estado, e situado nas seguintes coordenadas geográficas $06^{\circ} 03^{\prime} 30^{\prime \prime}$ de latitude Sul e $49^{\circ} 55^{\prime} 15^{\prime \prime}$ de longitude Oeste.

O clima da região é classificado como sendo super úmido, segundo a classificação de Köppen. De acordo Embrapa (2018), o solo da região é dado como Argissolo Vermelho-Amarelo. O período chuvoso segue de dezembro a maio registrando um total 1827 milímetros anuais de chuva, e a média da temperatura anual é $26^{\circ} \mathrm{C}$, e as médias das máximas e mínimas, seguem a ordem de $33^{\circ} \mathrm{C}$ e $22^{\circ} \mathrm{C}$.

Foi realizado duas arações e uma gradagem (plantio convencional). A semeadura foi feita por uma semeadora adubadora no dia 3 de março de 2019. A adubação foi feita com $350 \mathrm{~kg}$ de NPK, nas proporções de $110 \mathrm{~kg}$ de Nitrogênio, $150 \mathrm{~kg}$ de fosforo, e $90 \mathrm{~kg}$ de potássio, mais $50 \mathrm{~kg}$ de micronutrientes.

Foram avaliadas nove cultivares de milho com espaçamento com espaçamentos entre fileiras de $0,2 \mathrm{~m}$ entre plantas e 0,7 m entre fileiras, as cultivares avaliadas foram: C1-7742, C2- EXP.61, C3-6520, C4-713265, C5- EXP.83, C6-7641, C7-7132, C8- EXP.88, C9-774265.

Para a caracterização dos diferentes atributos de massa seca e massa úmida, utilizou-se 100 espigas de milho de cada parcela útil resultando num total de 900 amostras. A massa úmida da espiga (MAU) foi obtida com auxílio de uma balança de precisão, pesando a espiga de milho completa, em (g); a casca úmida da espiga (CAU) foi obtida pelo mesmo procedimento, retirando toda palha que envolve a espiga e a pesado em (g); o sabugo úmido (SAU) foi pesado por meio da retirada de todos os grãos da espiga em seguida foi pesado em (g); o grão úmido da espiga (GRU) foi pesado em (g) através da separação destes do sabugo.

Para a determinação da massa seca (MAS) foi triturado toda a espiga por meio de um moinho, em seguida levada à estufa para secagem a $60^{\circ} \mathrm{c}$. Utilizamos estufa de ventilação forçada. Em seguida, pesada na balança de precisão de $0,01(\mathrm{~g})$ para a obtenção das massas do grão seco da espiga (GRS). Foi utilizado uma faca inox para a separação dos grãos do sabugo e, em seguida colocados na estufa para secagem. Posteriormente, a determinação do sabugo seco (SAS), que foi levado ao moinho e seguida a estufa, sendo posteriormente pesado em (g); e finalmente para determinação da casca seca (CAS), onde estas são inicialmente moídas e levadas a estufa, em seguida pesada em (g).

A estatística descritiva foi realizada juntamente com a rede de correlações entre os atributos estudados por intermédio do Softwere RBio, Bhering (2017). A análise de trilha usada no presente trabalho utiliza o software GENES (Cruz 2013), buscando associar a relação entre variáveis diferente, de modo que a multicolinearidade seja extinta, atingindo sua eficiência.

\section{Resultados e Discussão}

A Figura 1 apresenta a rede de correlações entre os atributos estudados, destacando em verde as correlações positivas e em vermelho as correlações negativas. Vale frisar que a espessura da linha é influenciada pelo maior grau de correlação, ou seja, linhas mais grossas, correlações mais altas entre atributos. 
Figura 1 - Rede de correlações dos atributos estudados: massa úmida da espiga (MAU), casca úmida da espiga (CAU), sabugo úmido (SAU), grão úmido da espiga (GRU), massa seca da espiga (MAS), massas do grão seco (GRS), sabugo seco (SAS) e casca seca da espiga (CAS).

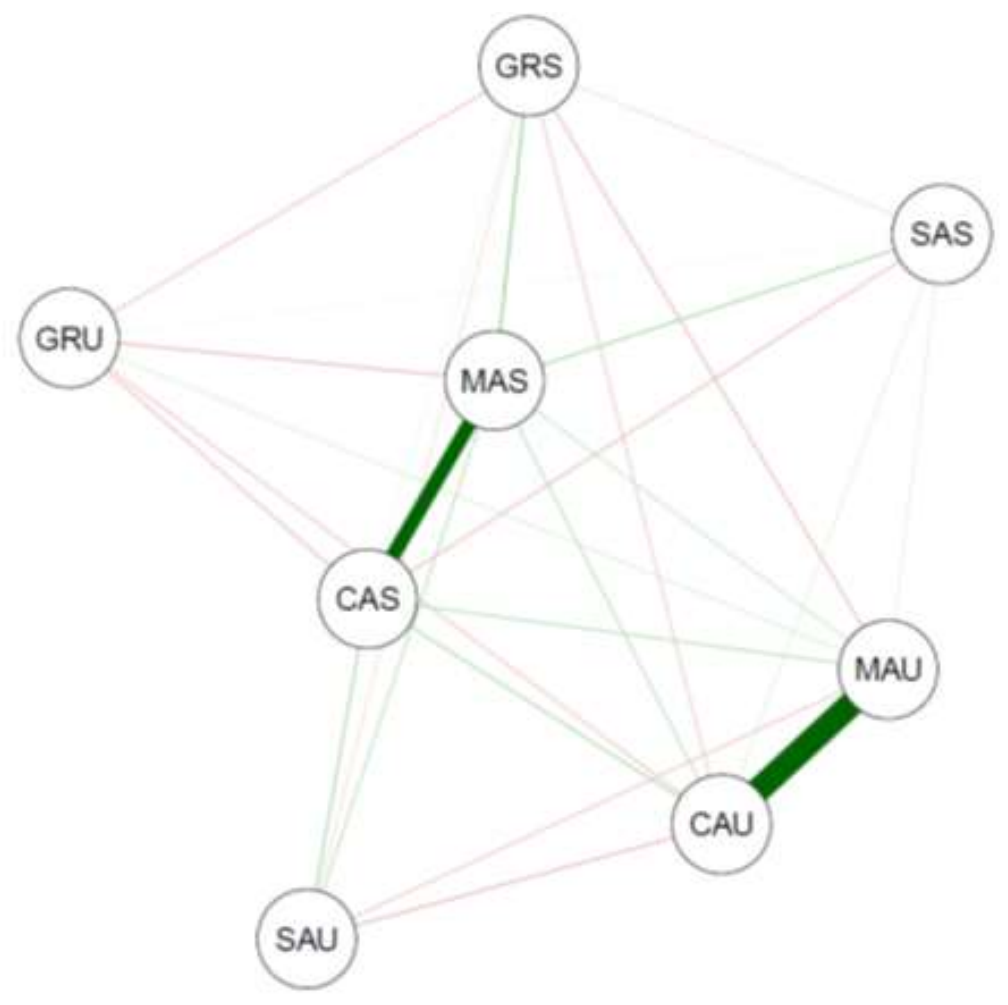

Fonte: Autores.

Analisando a Figura 1, observa-se que CAU e MAU apresentaram uma alta correlação positiva, indicando que um aumento da casca da espiga do milho implica em maior aumento da massa total da espiga, que se justifica pela maior proteção dos grãos à pragas. Essa relação positiva está diretamente relacionada à qualidade e comercialização das espigas de milho, pois visualmente elas se apresentam mais volumosas, e gerando maior rentabilidade na produção de seus derivados. Em seu estudo Nirupama (2020), afirma que fatores físicos do milho e seus respectivos coeficientes de rendimento apresentam alto grau de correlação positiva com a rentabilidade final da espiga.

Já a CAS e MAS também apresentaram grande correlação entre si, uma vez mesmo após o processo de secagem na estufa ambas não perderam qualidade e rendimento, sendo estes atributos relativamente proporcionais. Tal relação se traduz na fabricação de boas rações para alimentação animal como as silagens, além disso tem-se uma boa taxa de germinação dos grãos resultando em boas linhagens e uniformidade genética. A correlação entre produtividade de matéria seca e quantidade de grãos, corrobora com as demais correlações entre produção de grãos e produção de massa total (Ciappina, 2019). Para Biazus et al. (2018), a silagem de grãos úmidos é amplamente fornecida a várias espécies animais como suínos, ovinos, bovinos de leite e corte por apresentar-se altos valore nutricionais, suplementação energética e boa digestibilidade.

O sabugo é amplamente utilizado na produção de rações, suínas e bovinas, assim como na confecção de adubo e feno. Para Neumann et al. (2017) a utilização de híbridos de milho muito produtivos, gera quantidades significativas de massa de matéria seca.

Para a análise de trilha, foi utilizado o software Genes (Cruz, 2013), que parte de uma variável e extrai as correlações diretas e indiretas dinamizadas com as demais. A problemática é a "máscara" colocada pela presença da multicolinearidade, o que leva a quem analisa ter interpretações erradas (Pinheiro et al., 2021). 
Dessa forma, a análise de trilha objetiva tornar esses dados imparciais, bem como possibilitar que a descrição das propriedades seja idêntica a situação real. Abaixo a Figura 2, expressa o resultado da análise de trilha realizada.

Figura 2 - Análise de trilha entre a massa úmida da espiga (MAU), como variável principal e demais atributos: casca úmida da espiga (CAU), sabugo úmido (SAU), grão úmido da espiga (GRU), massa seca da espiga (MAS), massas do grão seco (GRS), sabugo seco (SAS) e casca seca da espiga (CAS).

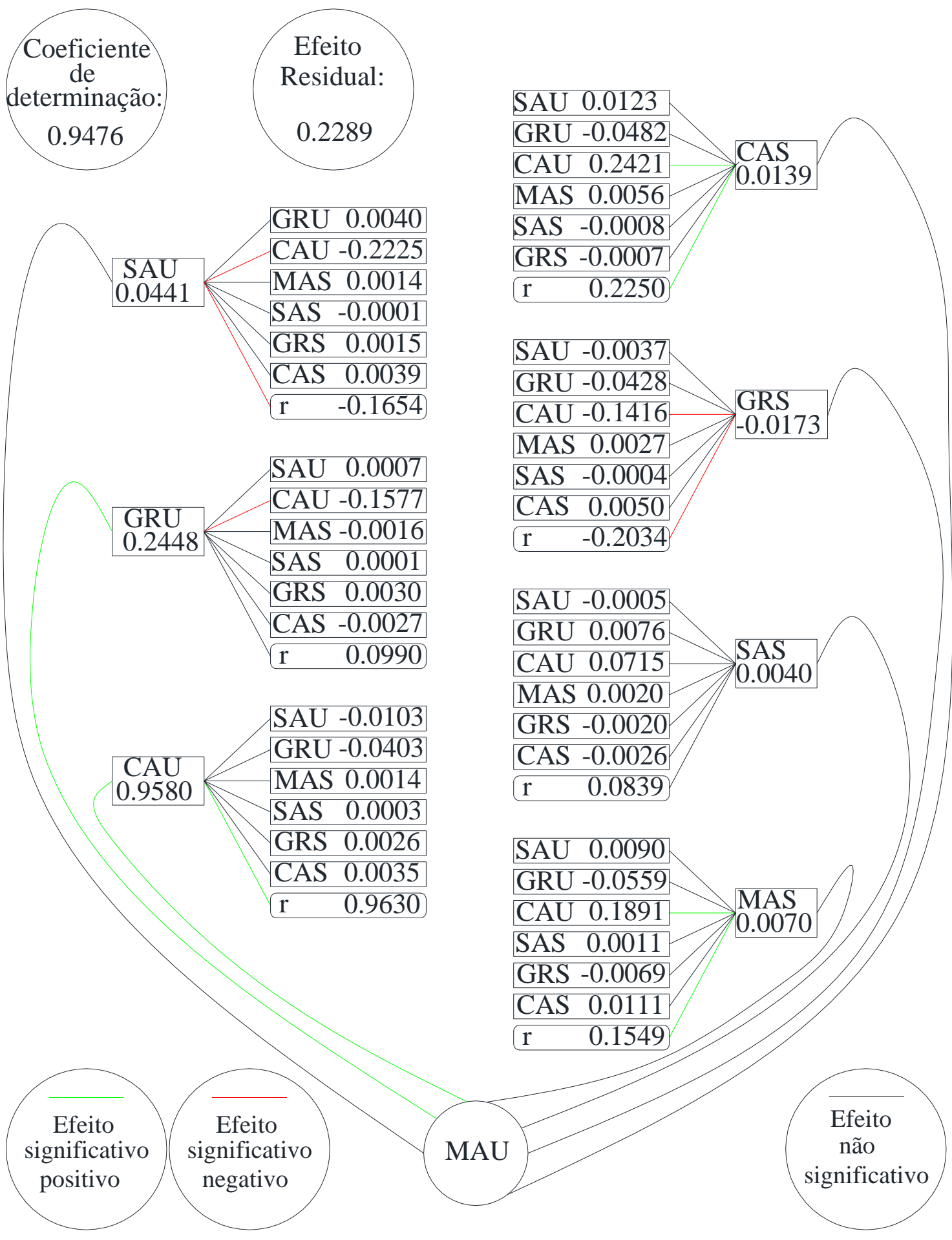

Fonte: Autores. 
Na Figura 2, podemos constatar um coeficiente de correlação alto, de 0,9476, expressando que os resultados são confiáveis. Pinheiro et al. (2021), encontraram coeficiente de correlação alto, de 0,7544 em estudo com atributos físicos no milho.

De forma direta, a análise de trilha possibilitou verificar que os atributos CAU e GRU são os atributos que melhor servem para avaliar a MAU. A massa úmida da espiga é importante atributo porque espigas mais pesadas tem potencial mais elevado para altas produtividades. Outro ponto a ser considerado como componente de rendimento é o peso da espiga, Chavan (2020), encontrou peso de espiga com coeficientes altos para espigas sem casca e espigas com casca. Isso reforça a relação intrínseca positiva que a MAU mantém com seus e seus respectivos atributos correlacionais positivos.

Ao analisarmos a Figura 2, de forma indireta, observamos que a CAU tem relação negativa significativa com o SAU e GRS, indicando que maiores umidades na casca produzem grão secos mais leves. O que é indesejável.

Por outro lado, a CAU tem correlação positiva e significativa com CAS e MAS. Este resultado mostra um aumento na umidade da casca da espiga de milho, implica em espigas mais pesadas.

\section{Conclusão}

De forma direta, a análise de trilha possibilitou verificar que os atributos casca úmida e grãos úmidos da espiga são os atributos que melhor servem para avaliar a massa úmida da espiga do milho.

Indiretamente, observamos via análise de trilha que a casca úmida tem correlação positiva com casca seca e massa seca da espiga, e correlação negativa com sabuco úmido e grãos secos da espiga.

\section{Agradecimentos}

Ao Centro Tecnológico de Agricultura Familiar de Parauapebas (CETAF), a Universidade Federal Rural da Amazônia (UFRA, Parauapebas, PA) e a Universidade Federal do Maranhão (UFMA, Chapadinha, MA). À Universidade Federal do Mato Grosso do Sul (UFMS, Chapadão do Sul, MS). O desenvolvimento deste trabalho contou com apoio da Coordenação de Aperfeiçoamento de Pessoal de Nível Superior - Brasil (CAPES) - Código de Financiamento 001. E ao apoio do Conselho Nacional de Desenvolvimento Científico e Tecnológico (CNPq), pelas bolsas concedidas aos autores.

\section{Referências}

Artuzo, F. D., Foguesatto, C. R., Machado, J. A. D., de Oliveira, L., \& de Souza, Â. R. L. (2019). O potencial produtivo brasileiro: uma análise histórica da produção de milho. Revista em Agronegócio e Meio Ambiente, 12 (2), 515-540. https://doi.org/10.17765/2176-9168.2019v12n2p515-540.

Bhering, L. L. (2017). Rbio: A Tool For Biometric And Statistical Analysis Using The R Platform. Crop Breeding and Applied Biotechnology, 17, 187-190. http://dx.doi.org/10.1590/1984-70332017v17n2s29.

Biazus, V. (2018). Rendimento, valor nutritivo e características fermentativas de silagens de grãos úmidos de cereais de inverno. Tese Doutorado - Universidade de Passo Fundo. http://tede.upf.br/jspui/handle/tede/1507.

Chavan, S., Bhadru, D., Swarnalatha, V. \& Mallaiah, B. (2020). Studies on Genetic Parameters, Correlation and Path Analysis for Yield and Yield Attributing Traits in Sweet Corn (Zea mays L. saccharata). Int. J. Curr. Microbiol. App. Sci, 9 (7), 1725-1734. https://doi.org/10.20546/ijcmas.2020.907.199.

Ciappina, A. L. (2019). Caracterização de híbridos e associação entre caracteres para produção de silagem em milho. Dissertação Mestrado - Universidade Federal de Goiás. https://repositorio.bc.ufg.br/tede/handle/tede/9996.

Companhia Nacional de Abastecimento, (2020) 7 (12). Décimo segundo levantamento. Levantamento da safra de grãos. file://C:/Users/55989/Downloads/GrosZsetembroZresumo.pdf.

Cruz, C. D. (2013). Genes Software-extended and integrated with the R, Matlab and Selegen. Acta Scientiarum. Agronomy, 38 (4), 547-552. 10.4025/actasciagron. v38i4.32629.

Empresa Brasileira de Pesquisa Agropecuária (2018). Sistema Brasileiro de classificação de solos: EMBRAPA (5a. ed.) rev. e ampl. ISBN: 978-85-7035-8172. 
Research, Society and Development, v. 10, n. 1, e41510111912, 2021

(CC BY 4.0) | ISSN 2525-3409 | DOI: http://dx.doi.org/10.33448/rsd-v10i1.11912

Nardino, M., Baretta, D., Carvalho, I. R., Follmann, D. N., Ferrari, M., Pelegrin, A. J. D., Souza, V. Q. D. (2017). Divergên cia genética entre genótipos de milho (Zea mays L.) em ambientes distintos. Revista de Ciências Agrárias, 40 (1), 164-174. http://dx.doi.org/10.19084/RCA16013.

Neumann, M., Leão, G. F. M., Coelho, M. G., Figueira, D. N., Spada, C. A., \& Perussolo, L. F. (2017). Aspectos produtivos, nutricionais e bioeconômicos de híbridos de milho para produção de silagem. Archivos de zootecnia, 66 (253), 51-57. https://doi.org/10.21071/az.v66i253.2125.

Nirupama, T., \& Marker, S. (2020). Genetic variation and inter-relationship among grain yield and its components in maize (Zea mays L.). Journal of Pharmacognosy and Phytochemistry, 9 (4), 717-720. https://www.phytojournal.com/archives/2020/vol9issue4/PartJ/9-4-81-105.pdf.

Pinheiro, L. S, Silva, R. C., Vieira, R. C., Aguiar, R. O., Nascimento, M. R., \& Vieira, M. M. Análise de trilha dos atributos físicos de milho (Zea mays L.) em sistema de cultivo convencional. Research, Society and Development, 10(1), $2021 \mathrm{http} / / / \mathrm{dx} . \mathrm{doi} . \mathrm{org} / 10.33448 / \mathrm{rsd}-\mathrm{v} 10 \mathrm{i1} .10832$.

Sukumar, K., Hemalatha, V., Reddy, V. N., \& Reddy, S. N. (2019). Character Association and Path Analysis for Yield and Quality Traits in Quality Protein Maize (Zea mays L.). Int. J. Curr. Microbiol. App. Sci, 8 (8), 3097-3110. https://doi.org/10.20546/ijcmas.2019.808.359.

Verma, V., Yadav, M. S., Kumar, A., \& Gathiye, G. S. (2020). Correlation and path analysis for seed yield and components traits in maize (Zea mays L.). Journal of Pharmacognosy and Phytochemistry, 9 (1), 2278-2280. https://www.phytojournal.com/archives/2020/vol9issue1/PartAL/9-1-476-770.pdf. 